\title{
Transient response of a packed bed for thermal energy storage
}

\author{
DONALD E. BEASLEY $\dagger$ and JOHN A. CLARK \\ Department of Mechanical Engineering and Applied Mechanics, University of Michigan, \\ Ann Arbor, MI 48109, U.S.A.
}

(Received 24 November 1983)

\begin{abstract}
An analysis, with experimental results, for the transient response of a packed bed thermal storage unit is presented. The analysis is in two spatial dimensions and considers the influence of both axial and radial thermal dispersion for arbitrary time and radial variations in the inlet fluid temperature. Both charging and recovery modes are included. Spatial variations in void fraction are found to have significant influence on the dynamic response of both fluid and solid temperatures. An unconditionally stable numerical model is developed that predicts the two-dimensional transient response of both solid and fluid phases. The influence of radial velocity variations, wall heat capacity and wall thermal losses are considered. The analysis is valid for fluids of various Prandtl numbers. Experimental measurements of temperature distributions in a randomly packed bed of uniform spheres, with air as the working fluid, compare favorably with the analytical results over a broad range of Reynolds numbers. Results are presented for full-size rock beds which indicate pronounced effects of void distribution in such systems.
\end{abstract}

\section{INTRODUCTION}

IN ENERGY systems where a temporal difference exists between the supply of energy and its utilization, some form of energy storage is necessary to insure the continuity of a thermal process. Both waste heat recovery and solar thermal energy systems are primary applications for thermal energy storage. For air systems and in some cases liquid systems, such as solar domestic water and space heating, a packed bed provides effective thermal energy storage. In general, a packed bed receives energy during its charging cycle from a heated fluid flowing downward. If the energy source is a solar collector the inlet fluid temperature will vary continuously with time during charging. During a typical charging cycle, the inlet fluid temperature to the bed increases to a maximum around solar noon. Subsequently the collector outlet temperature, and thus the storage inlet fluid temperature, decreases until energy is no longer capable of being added to storage. This temporal inlet fluid temperature variation establishes a thermocline in the storage bed with a maximum temperature in the upper regions. During the period between charging and recovery, some degradation of this thermocline will occur by diffusional processes. If the temperature gradients are sufficiently large, the onset of convective motion of the fluid will occur, and accelerate the thermocline degradation. Thermocline degradation reduces the available energy in the bed. Energy is recovered from the bed by reversing the direction of fluid flow.

The determination of the transient response of a packed bed, subject to an arbitrarily time-varying inlet

† Present address : Department of Mechanical Engineering, Clemson University, Clemson, South Carolina, U.S.A. fluid temperature, is necessary for evaluating its thermal performance, for both charging and recovery modes. To date most analytical or numerical models of packed beds have been spatially lumped or onedimensional (1-D). The present study includes two spatial dimensions to describe the dynamics of packed beds.

\section{BACKGROUND LITERATURE}

Fluid flow and heat and mass transfer analysis of packed beds and other porous media derives from many applications, such as the flow of ground water, separation and distillation in chemical processes, and the curing of composite materials, among others. Considerable analysis of heat and mass transfer in packed beds used as chemical reactors has been performed, focusing largely on the steady operating conditions, but including transient analysis for (1-D) spatial distributions of temperature and concentration. Recently, a number of studies has examined the packed bed for thermal energy storage. Table 1 summarizes the present status of thermal storage modeling of packed beds, including both analytical and numerical studies, and experimental investigations. Single-phase models assume the instantaneous solid and fluid temperatures to be equal; two-phase models allow these temperatures to be different, with the interphase heat transfer described by a mean heat transfer coefficient. The majority of work has focused on the one spatial dimensional, time-dependent, twophase model first studied by Schumann [3] for fairly simple initial and boundary conditions. This model predicts the mean fluid and solid temperatures at a given cross-section as a function of axial position and time, incorporating the solid-fluid heat transfer 


\section{NOMENCLATURE}

a interphase surface area per unit volume,

$$
6(1-\varepsilon) / D_{\mathrm{s}}
$$

A $u \Delta t / 2 \Delta x$

$A_{0}$ bed cross-sectional area

$A_{\mathrm{w}}^{\mathrm{o}} \quad$ outer wall surface area per unit length

$A_{\mathrm{w}}^{\mathrm{i}} \quad$ inner wall surface area per unit length

$A_{0}^{\prime} \quad 2 \pi R_{\mathrm{w}} / \pi\left(R_{\mathrm{w}}^{2}-R_{0}^{2}\right)$

$A_{\mathrm{i}}^{\prime} \quad 2 \pi R_{0}^{\mathrm{w}} / \pi\left(R_{\mathrm{w}}^{2}-R_{0}^{2}\right)$

$B \quad \kappa \Delta t$

$c \quad$ fluid heat capacity

$c_{\mathrm{s}} \quad$ solid heat capacity

$C_{\mathrm{w}} \quad c_{\mathrm{w}} \pi\left(R_{\mathrm{w}}^{2}-R_{\mathrm{o}}^{2}\right)$

C $\Delta t \kappa /(1+\gamma \Delta t) x$

$C_{0}$ proportionality constant, turbulent dispersion contribution to effective conductivity

$C_{1}$ constant in equation (10)

$C_{2}$ constant in equation (10)

D $\quad \kappa \gamma(\Delta t)^{2} /(1+\gamma \Delta t)$

$D_{0}$ container diameter

$D_{\text {s }}$ particle diameter

E $\quad 1.0+B-D+2 L+2 N$

$F$ Frössling number, $(N u-2) / \operatorname{Re}_{0}^{1 / 2} \operatorname{Pr}^{1 / 3}$

$h$ interphase heat transfer coefficient

$h_{\mathrm{w}} \quad$ wall heat transfer coefficient

$k_{\mathrm{e}}^{0} \quad$ stagnant bed effective thermal conductivity

$k_{\mathrm{e}}^{R} \quad$ radial effective thermal conductivity

$k_{\mathrm{e}}^{x} \quad$ axial effective thermal conductivity

$k_{\mathrm{f}} \quad$ fluid thermal conductivity

$k_{\mathrm{w}} \quad$ wall thermal conductivity

$L \quad k_{\mathrm{e}}^{R} \Delta t / \rho c\left(\Delta R_{j}\right)^{2}$

$m$ number of radial divisions

$M \quad k_{\mathrm{e}}^{R} \Delta t / 2 \rho c R_{i}^{*} \Delta R_{i}$

$n$ number of axial nodes

$N \quad k_{\mathrm{e}}^{x} \Delta t / \rho c(\Delta x)^{2}$

$N u \quad$ Nusselt number, $h D_{\mathrm{s}} / k_{\mathrm{f}}$

$P$ pressure
$P e_{0} \quad$ superficial Peclet number, $\rho c u_{0} L / k_{\mathrm{f}}$

$P e_{i} \quad \rho c u_{0} L / k_{\mathrm{e}}^{\mathrm{i}}$

$R$ radial direction variable

$R_{0} \quad$ outer radius of the bed

$R_{\mathrm{w}} \quad$ outer radius of wall

$R_{i}^{*} \quad$ radius of node $i$

$\Delta R_{i}$ radial increment $i$

$R e_{0}$ superficial Reynolds number, $u_{0} D_{\mathrm{s}} / v$

$R_{\mathrm{e}}^{\prime} \quad R e_{0} /\left(\varepsilon-\varepsilon_{\mathrm{b}}\right)$

$t$ time

$t_{0} \quad$ time of charging or recovery

$\Delta t \quad$ time step size

$T$ fluid temperature

$T_{\infty}$ ambient temperature

$u \quad$ interstitial fluid velocity, $u_{0} / \varepsilon$

$u_{0} \quad$ superficial velocity

$U_{\infty}$ overall heat transfer coefficient from the wall

$x \quad$ axial direction variable

$\Delta x$ axial spatial increment.

Greek symbols

$\alpha_{\mathrm{t}} \quad$ apparent turbulent intensity level

$\beta_{1} \quad\left(k_{\mathrm{w}} / \rho_{\mathrm{w}} c_{\mathrm{w}}\right)\left(\Delta t /(\Delta x)^{2}\right)$

$\beta_{2} \quad u_{\infty} A_{0}^{\prime} \Delta t / \rho_{\mathrm{w}} c_{\mathrm{w}}$

$\beta_{3} \quad A_{1}^{\prime} \Delta t / \rho_{\mathrm{w}} c_{\mathrm{w}}$

$\gamma \quad 6 h / \rho_{\mathrm{s}} c_{\mathrm{s}} D_{\mathrm{s}}$

$\varepsilon \quad$ local void fraction

$\varepsilon_{\mathrm{b}} \quad$ void fraction of stagnant fluid regions

$\bar{\varepsilon} \quad$ average void fraction

$\kappa h a / \rho c \varepsilon$

$\mu \quad$ dynamic viscosity

$v \quad$ kinematic viscosity

$\rho \quad$ fluid density

$\rho_{\mathrm{s}} \quad$ solid density

$\rho_{w} \quad$ wall density

$\chi \quad$ solid temperature

$\psi \quad$ wall temperature. coefficient as a parameter. Recently Shitzer and Levy [22] have extended the basic Schumann analysis to account for a time variation in inlet fluid temperature using the Duhamel superposition technique. Their results, which compare favorably with experimental measurements, are applicable to a charging mode only. A large number of studies exist on convective heat transfer and pressure drop in packed beds and correlations for various parameter ranges are reported. Experimental data exist over a wide range of Reynolds number and for a variety of geometries. A comprehensive summary of these studies is given by Balakrishnan [27].

Some analyses have attempted to account for twoand three-dimensional (2- and 3-D) effects. Martin [28] divided a cylindrical bed, packed with uniform spheres, into a central core and a near-wall region, with a higher void fraction near the boundary than in the core of the bed. Martin used an assumed radial variation of void fraction to predict a cross-sectionally averaged heat transfer coefficient. Gross et al. [16] utilized Martin's correlation to predict the axial variation of temperature within the bed. Their explicit numerical method is most applicable to liquid systems, but, as the authors state, is not as well suited to air systems. The present authors have found that computing times for this approach [16] are greatly increased for large ratios of solid-fluid heat capacity.

Amundson [23] analyzed the 2-D temperature distribution in a cylindrical packed bed chemical reactor with energy losses at the wall, and energy generation in the solid phase. For constant velocity, 
Table 1. Survey of thermal storage models

\begin{tabular}{lcccc}
\hline \multicolumn{5}{c}{ One-dimensional, single-phase dynamic models } \\
Source & Year & Analytical & Numerical & Experimental \\
Vortmeyer and Schaefer [1] & 1974 & $*$ & & \\
Riaz [2] & 1977 & $*$ &
\end{tabular}

One-dimensional, separate phases dynamic model

\begin{tabular}{|c|c|c|c|c|}
\hline & & & & \multirow{2}{*}{ Experimental } \\
\hline Source & Year & \multirow{2}{*}{$\underset{*}{\text { Analytical }}$} & \multirow{2}{*}{ Numerical } & \\
\hline Schumann [3] & 1929 & & & \\
\hline Furnas [4] & 1930 & & & * \\
\hline Clark and Arpaci [5] & 1976 & * & & \\
\hline Mumma and Marvin [6] & 1976 & & * & \\
\hline Schmidt and Szego [7] & 1976 & & * & \\
\hline Hughes et al. [8] & 1976 & & * & \\
\hline Burch et al. $[9]$ & 1976 & & * & \\
\hline Yang and Lee [10] & 1977 & * & & \\
\hline Eshleman et al. [11] & 1977 & & * & \\
\hline Clark et al. [12] & 1977 & & * & \\
\hline Von Fuchs [13] & 1979 & & * & \\
\hline Pomeroy [14] & 1979 & * & & \\
\hline White and Korpela [15] & 1979 & * & & \\
\hline Gross et al. $[16]$ & 1980 & & * & \\
\hline Jones and Hill (NBS) [17] & 1980 & & & * \\
\hline Spiga and Spiga [18] & 1981 & * & & \\
\hline Courtier and Farber [19] & 1982 & & * & \\
\hline Saez and McCoy $[20,21]$ & 1983 & & * & \\
\hline Shitzer and Levy [22] & 1983 & $*$ & & * \\
\hline \multicolumn{5}{|c|}{ Two-dimensional separate phases dynamic models } \\
\hline Source & Year & Analytical & Numerical & Experimental \\
\hline Amundson [23] & 1956 & & & \\
\hline Vanden Broek and Clark [24] & 1976 & & & * \\
\hline Robertson and Cavendish [25] & 1981 & & * & \\
\hline Clark and Beasley [26] & 1982 & & * & \\
\hline Beasley and Clark (Present) & 1983 & & * & * \\
\hline
\end{tabular}

void fraction, fluid properties, and transport coefficients the transient solutions for various boundary and initial conditions are obtained. The effect of including an axial diffusion term is examined. The results are mathematical in form without experimental verification. Robertson and Cavendish [25] examined the 2-D response of catalytic converters and packed beds for the case of uniform void fraction, but nonuniform inlet conditions.

\section{RADIAL VARIATION IN PACKED BEDS}

The models previously discussed assumed the void fraction, velocity and transport coefficients to be spatially uniform at a given cross-section. However, measurements indicate that the void fraction, $\varepsilon$, has a significant radial variation. Cylindrical and rectangular beds, randomly packed with uniform spheres display damped oscillatory variations of $\varepsilon$ with radius for approximately five particle diameters from a wall [29]. The difference between the radius of curvature of the wall and that of the spheres causes the void fraction to be 1.0 at the wall which introduces local order into the otherwise random packing.

The mean void fraction, $\bar{\varepsilon}$, for a packed bed is a function of the bed-to-particle diameter ratio, $D_{0} / D_{\mathrm{s}}$.
The variation of $\bar{\varepsilon}$ with $D_{0} / D_{\mathrm{s}}$ for a randomly packed bed of uniform spheres is demonstrated by the data of Beavers et al. [30] and from the present study, in Fig. 1.

Measurements of velocity profiles in randomly packed beds of uniform spheres by Schwartz and Smith [31] and others, show preferential flow in the near-wall region. Observations of the velocity profile at the exit of a square column by Newell and Standish [32] demonstrate the variations of velocity with radial location, Fig. 2, with proposed profiles added by the present authors. Preferential flow in the near-wall region for the packing of uniform spheres is clearly a result of the wall effect (curve A). The presence of a second size sphere in the packing is to produce two peaks in the velocity profile, at the wall and the centerline (curve B). Similar behavior is observed for randomly shaped coke particles (curve $\mathrm{C}$ ). From these measurements it is inferred that the void fraction at the centerline is increased for both the binary mixture of spheres and the coke. Evidently the periodic behavior of the void variation near the wall is propagated into the bed out-of-phase from opposing walls, producing an incongruity at the centerline and thus an increased void fraction when a size distribution exists.

The momentum transfer associated with the wallfluid interaction is different than that associated with 


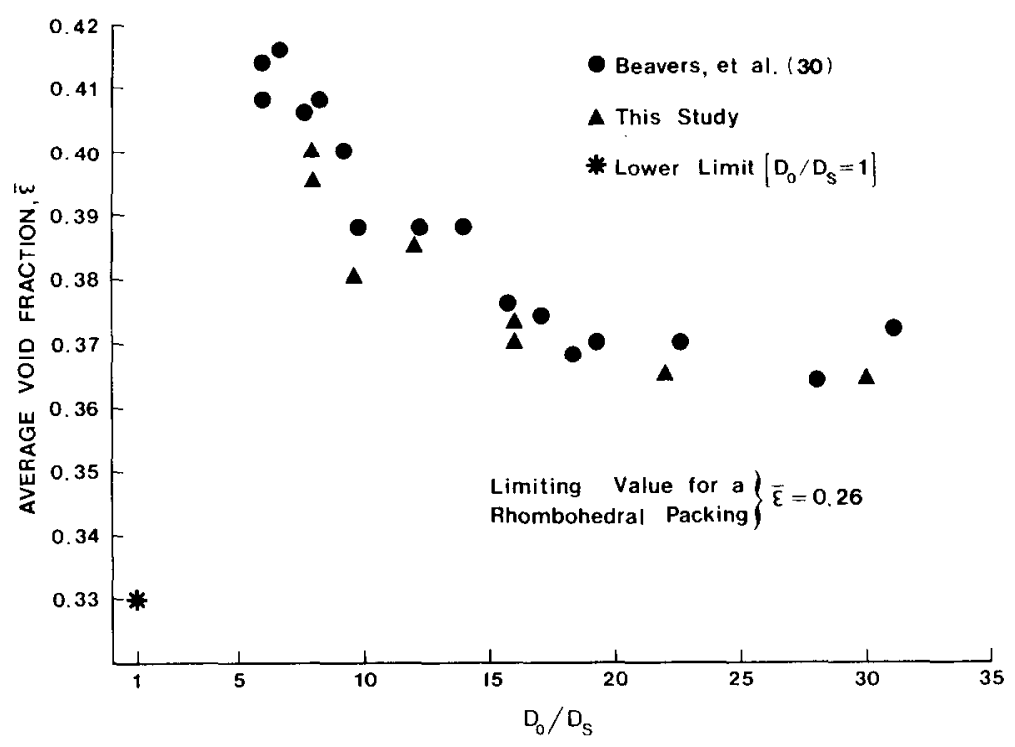

Fig. 1. Average void fraction as a function of container diameter to particle diameter (uniform spheres).

the matrix of spheres in the interior of the bed. Mickley et al. [33] have shown that even if a constant void exists, produced by using half and quarter spheres at the wall in a regular packing, there is still less resistance to flow at the near-wall region.

These effects indicate that at least a 2-D model of the temperature distribution in a packed bed is necessary for a complete description of the dynamics of the bed. Beds having a square cross-section will have a third spatial dimensional effect introduced by corners and probably will require a more complex analysis to allow for complete modeling. This will be especially true for all beds having a particle size and shape distribution. In these cases it seems apparent that some form of statistical description of the packing will be necessary for performance modeling.

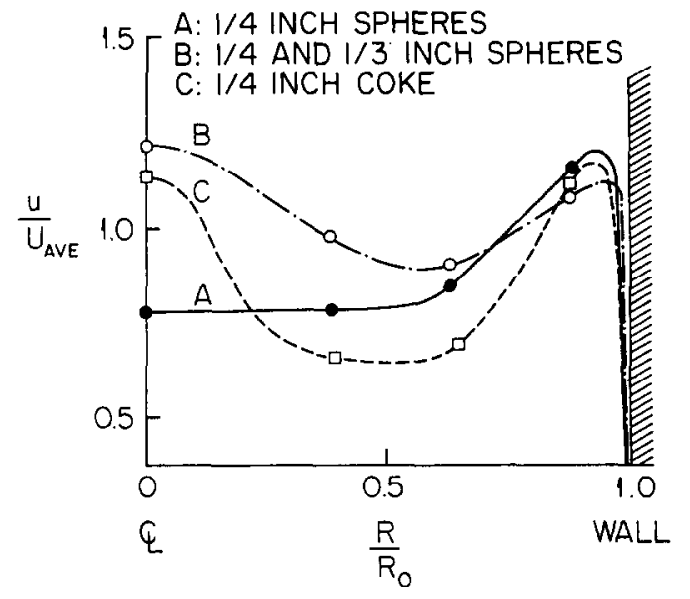

FIG. 2. Velocity profiles in packed beds, data from Newell and Standish [32] for a square cross-section.

\section{ANALYSIS AND MODELING}

The following axisymmetric equations govern the temperature distribution in a 2-D packed bed, where the void fraction, $\varepsilon$, velocity, $u$, and transport coefficients vary spatially with radial location

Fluid phase

$$
\begin{aligned}
\frac{\partial T}{\partial t}+u \frac{\partial T}{\partial x}=\frac{k_{\mathrm{e}}^{x}}{\rho c} \frac{\partial^{2} T}{\partial x^{2}}+\frac{k_{\mathrm{e}}^{R}}{\rho c}\left(\frac{1}{R} \frac{\partial T}{\partial R}\right. & \left.+\frac{\partial^{2} T}{\partial R^{2}}\right) \\
& +\frac{h a}{\rho c \varepsilon}(\chi-T)
\end{aligned}
$$

Solid phase

$$
\rho_{\mathrm{s}} c_{\mathrm{s}}(1-\varepsilon) \frac{\partial \chi}{\partial t}=h a(T-\chi)
$$

Wall

$\rho_{\mathrm{w}} C_{\mathrm{w}} \frac{\partial \psi}{\partial t}=k_{\mathrm{w}} \frac{\partial^{2} \psi}{\partial x^{2}}+h_{\mathrm{w}} A_{\mathrm{w}}^{\mathrm{i}}(T-\psi)+U_{\infty} A_{\mathrm{w}}^{\mathrm{o}}\left(T_{\infty}-\psi\right)$.

These equations include the effects of radial and axial thermal dispersion, wall heat capacity, and axial conduction in the wall, as well as wall energy losses from the bed. A discussion of the inclusion of diffusion terms in the fluid and/or solid equation is found in ref. [34].

The governing equations are approximated by implicit finite-difference equations. The simplicity of the solid equation allows an explicit statement for the solid temperature at the future time step, $n+1$

$$
\chi_{i, j}^{n+1}=(1+\gamma \Delta t)^{-1}\left(\chi_{i, j}^{n}+\gamma \Delta t T_{i, j}^{n+1}\right)
$$

where $i$ and $j$ denote radial and axial location of the appropriate node, and $n$ indicates the present time step. 
Substituting equation (4) for the solid temperature at time step $n+1$ into the finite-difference form of equation (1), yields the following form for the fluid temperature at the general node

$$
\begin{aligned}
E \cdot T_{i, j}^{n+1}+(A-N) \cdot T_{i, j+1}^{n+1}-(A+N) \cdot T_{i, j-1}^{n+1} \\
\quad-(L+M) \cdot T_{i+1, j}^{n+1}-(L-M) T_{i-1, j}^{n+1} \\
\quad=T_{i, j}^{n}+C \cdot \chi_{i, j}^{n} .
\end{aligned}
$$

For the nodes at the outer radial location, $i=m$, equation (5) must be modified to include the convective energy exchange with the wall. At $i=m$ the radial derivatives are approximated by backwards differences, and the following term added to equation (5)

$$
\left(\frac{h_{\mathrm{w}} \Delta t}{\rho c \varepsilon}\right)\left(\frac{R_{0}}{R_{m}^{*} \Delta R_{m}}\right)\left(\psi_{j}^{n+1}-T_{m, j}^{n+1}\right) .
$$

The finite-difference equation for the wall is, for the general node

$$
\begin{array}{r}
{\left[1.0+2 \beta_{1}+h_{\mathrm{w}} \beta_{3}+\beta_{2}\right] \psi_{j}^{n+1}-\beta_{1}\left(\psi_{j+1}^{n+1}+\psi_{j-1}^{n+1}\right)} \\
-h_{\mathrm{w}} \beta_{3} T_{m, j}^{n+1}=\psi_{j}^{n}+\beta_{2} T_{\infty} .
\end{array}
$$

The boundary conditions at the inlet and outlet must be specified for the computational scheme. Most previous investigators have simply assigned the fluid temperature at the first node to be equal to the forcing inlet fluid temperature. However, since the first node has associated with it a mass of solid, this is not physically correct. Burch et al. [9] used a convective boundary condition at the inlet face of the bed, although the physical significance of their transport coefficient is not clear. The formulation used here utilizes a central difference approximation for both $\partial^{2} T / \partial x^{2}$ and $\partial T / \partial x$. Thus, at the inlet node the difference approximation contains a temperature, $T_{i-1, j}^{n+1}$, which is located outside the packing. This temperature is assigned the value of the forcing (inlet) fluid temperature, an approach which seems in better accord with the physical circumstances. The velocity distribution within the bed is derived from a modified form of the Ergun equation [35]. Stanek and Szekely [36] and Szekely and Poveromo [37] have successfully used a vectorized form of the Ergun equation to predict 3-D flows in packed beds. Thus, the following equation is used to establish the pressure gradient which then governs the radial variations in axial velocity for $1-D$ flow

$$
-\frac{\partial P}{\partial x}=\frac{150 \mu(1-\varepsilon)^{2}}{D_{\mathrm{s}}^{2} \varepsilon^{3}} u_{0}+1.75 \frac{\rho(1-\varepsilon)}{D_{\mathrm{s}} \varepsilon^{3}} u_{0}^{2}
$$

where $\varepsilon$ is a function of $R$. A recent review of the variability in the geometry dependent constants, 150 and 1.75 is given by MacDonald et al. [38]. The appropriate boundary condition for equation (8) is a constant pressure difference across the bed.

Once the velocity distribution in the bed is established, the difference equations yield a set of simultaneous linear equations for the fluid and wall temperatures at each time step. The coefficient matrix is updated after each iteration, with fluid properties and transport coefficients appropriate to the local conditions. The solution of the linear equations is accomplished utilizing a matrix decomposition method for banded matrices, which reduces storage requirements and computing times. The resulting implicit computational routine is unconditionally stable. Computational experiments demonstrate that the algorithm is relatively insensitive to spatial increment sizes. However, careful attention to time step size is necessary to insure convergence. Comparison of this algorithm, for the 1-D case, with predictions using ROCKBED [12] and with a version of the method proposed by Gross et al. [16] developed by the present authors indicate the validity of the present algorithm [26].

\section{TRANSPORT PROPERTIES AND COEFFICIENTS}

The interphase heat transfer coefficient, $h$, has been widely reported in the literature and numerous correlations exist. Galloway and Sage [39] developed the following form for packed, distended, and fluidized beds, which is used in the present study

$$
\begin{aligned}
F s\left(\varepsilon-\varepsilon_{\mathrm{b}}\right)^{1 / 2}= & 0.5483 \\
& +\left[0.1212 \alpha_{1}\left(\alpha_{\mathrm{t}}-0.04595\right)\right. \\
& +0.001656]\left(\operatorname{Re}^{\prime}\right)^{1 / 2} \operatorname{Pr}^{1 / 6} \\
& \left(R e_{0}<5000\right) .
\end{aligned}
$$

For a particular type of packing equation (9) results in the following correlation

$$
N u=2.0+C_{1} \operatorname{Re}_{0}^{1 / 2} \operatorname{Pr}^{1 / 3}+C_{2} \operatorname{Re}_{0} \operatorname{Pr}^{1 / 2} .
$$

For a randomly packed bed of spheres $C_{1}$ and $C_{2}$ are 1.354 and 0.0326 , respectively [39].

The fluid phase effective thermal conductivities, $k_{\mathrm{e}}^{x}$ and $k_{\mathrm{e}}^{R}$, embody convective transport due to turbulent dispersion in the fluid phase, and pure conduction in both phases. The following correlation, by Yagi and Kunii [40], is assumed to govern $k_{\mathrm{e}}^{i}$

$$
P e_{i}=\frac{P e_{0}}{C_{0} P e_{0}+k_{\mathrm{e}}^{0} / k_{\mathrm{f}}} .
$$

Values of $C_{0}$ in the radial case are given by Baddour and Yoon [41]. The presence of the wall suppresses turbulent dispersion contributions in the near-wall region, such that in the central regions of the bed $C_{0}=1 / 11$, while in the near-wall region $C_{0}=0.01$. In the axial case, measured values of $C_{0}$ range from 0.2 to 1.0. An intermediate value of 0.5 is chosen for this work. Finally a value of $k_{\mathrm{e}}^{0} / k_{\mathrm{f}}$ must be determined. The stagnant bed thermal conductivity is a function of the fluid and solid phase thermal conductivities, as well as the bed geometry. For rock-air, or similar systems $k_{e}^{0} / k_{\mathrm{f}}=10$.

The wall heat transfer coefficient is taken from a correlation by Yagi and Kunii [42]. 


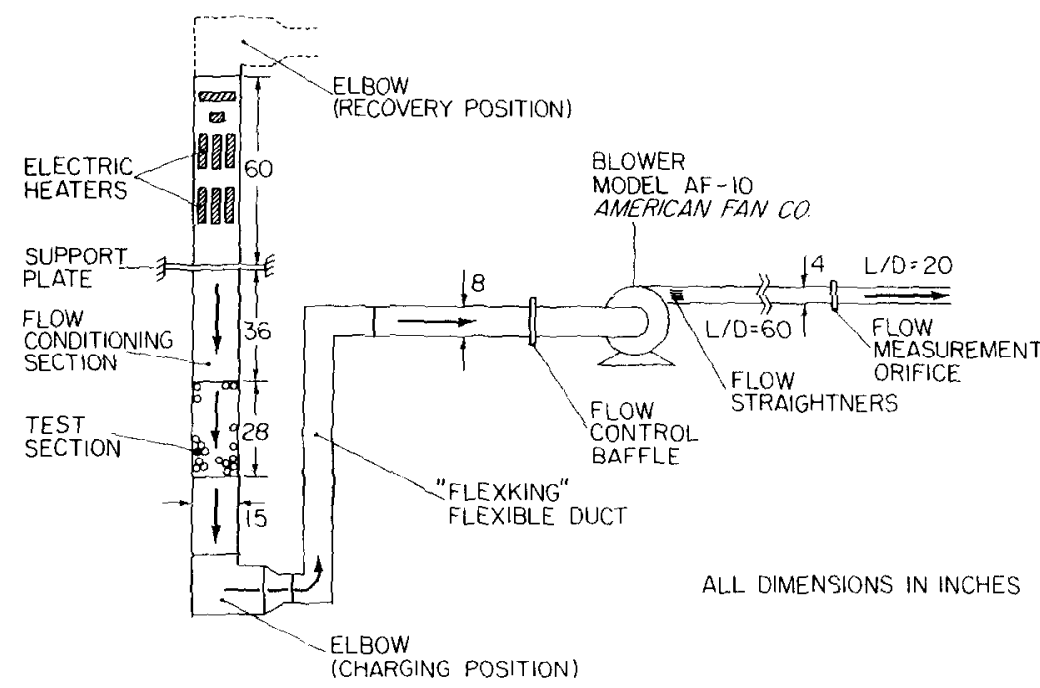

FIG. 3. Experimental apparatus.

\section{DESCRIPTION OF EXPERIMENT}

To determine the 2-D, transient temperature response experimentally for a packed bed having a welldefined geometry, a cylindrical bed is chosen which is randomly packed with spheres having uniform size and thermal properties. A schematic of the experimental apparatus is shown in Fig. 3 [43]. Airflow is produced by a blower, and flow reversal is accomplished utilizing the removable elbow/flexible hose connection. The apparatus provides a controlled, time-varying, radially distributed but azimuthally uniform inlet fluid temperature.

The packing is formed by $0.5 \mathrm{in} .(1.26 \mathrm{~cm})$ soda lime glass spheres, with a measured density of $155.2 \mathrm{lb} \mathrm{ft}^{-3}$ $\left(2486 \mathrm{~kg} \mathrm{~m}^{-3}\right)$. The bed-to-particle diameter ratio is 30 ,

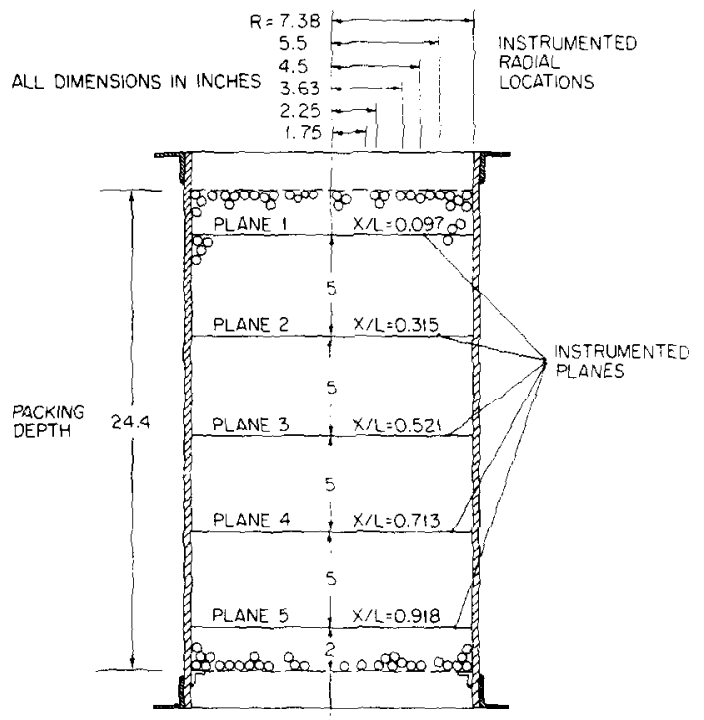

FIG. 4. Test section and instrumented locations. which provides for a central region essentially free from the wall effect on void fraction. Table 2 lists the characteristics of the packing and container.

Figure 4 shows radial and axial locations of the 60 copper-constantan thermocouples ( 30 gage), placed in the bed. Solid temperature measurements are made using instrumented aluminum spheres having a volumetric heat capacity $\left(\rho c_{p} V\right)$ equal to that of the glass spheres.

Simultaneous fluid-solid temperature measurements during a transient allowed determination of the local heat transfer coefficient, using the solid spheres as dynamic calorimeters.

The fluid flow rate was measured by an orifice plate having an uncertainty of $\pm 2.0 \%$ in accordance with ASME standards [44].

Thermocouple data were collected by a John Fluke Co. Model 2240B datalogger, which provided for selective, sequential, programmable scanning of the available 60 channels. The present data were obtained using variable sequential scanning rates from 30 to $120 \mathrm{~s}$ for all sensors. Electronic reference junction

Table 2. Characteristics of bed

\begin{tabular}{|c|c|}
\hline Bed length & $2.03 \mathrm{ft} .(0.6191 \mathrm{~m})$ \\
\hline Bed diameter & $1.23 \mathrm{ft} .(0.375 \mathrm{~m})$ \\
\hline Packing material & Soda lime glass \\
\hline Particle diameter & 0.495 in. $(1.26 \mathrm{~cm})$ \\
\hline Particle density & $155.2 \mathrm{lb} \mathrm{ft.}^{-3}\left(2486 \mathrm{~kg} \mathrm{~m}^{-3}\right)$ \\
\hline Particle spccific heat & $\begin{array}{l}0.185 \mathrm{Btu} \mathrm{lb}^{-1}{ }^{\circ} \mathrm{F}^{-1} \\
\left(774.2 \mathrm{~J} \mathrm{~kg}^{-1} \mathrm{~K}^{-1}\right)\end{array}$ \\
\hline Mean void fraction & $0.364 \pm 0.01$ (experimental) \\
\hline Wall material & Steel \\
\hline Wall thickness & $0.125 \mathrm{in} .(3.175 \mathrm{~mm})$ \\
\hline \multicolumn{2}{|c|}{$\begin{array}{l}\text { Void distribution for PACKBED } \\
\qquad \begin{array}{ll}\left(R / R_{0}\right)<0.932 & \varepsilon=0.364 \\
\left(R / R_{0}\right)>0.932 & \varepsilon=0.460\end{array}\end{array}$} \\
\hline
\end{tabular}


compensation and $\mathrm{A} / \mathrm{D}$ conversion allow serial data output to an IBM personal computer with an accuracy of $\pm 0.5^{\circ} \mathrm{F}\left( \pm 0.3^{\circ} \mathrm{C}\right)$. The temperature-time data were recorded and made available on demand for plotting using the University's mainframe computer for comparison with calculations by PACKBED [43].

\section{RESULTS}

Results of the 2-D model PACKBED are compared with experimental measurements from three different studies. The experimental bed provides detailed transient temperature distributions during charging and recovery modes. This bed has a large wall heat capacity, high wall thermal conductivity, a radially distributed inlet fluid temperature, and a large packing volume that is $38 \mathrm{~cm}$ in diameter and $122 \mathrm{~cm}$ long.

Comparisons are also made with measurements from the small cylindrical laboratory-scale bed of Vanden Broek and Clark [24] $(8.0 \mathrm{~cm}$ diameter $\times 24.0$ $\mathrm{cm}$ ), filled with uniform steel spheres, $0.56 \mathrm{~cm}$ in diameter. A thin PVC container provides essentially no wall heat capacity or longitudinal wall conduction. The bed is subjected to a step change in inlet fluid temperature. Solid temperatures at various axial locations and the mixed mean exit fluid temperatures are measured.

The third comparison is made with centerline fluid temperature measurements for a commercial size rock bed [17] subject to an approximate step change in inlet fluid temperature.

\section{Energy balance}

The consistency of the computational scheme is demonstrated by comparison of 1-D predictions with those of other models [43], and by performing an overall energy balance at each time step. The energy balances were obtained by selecting a control volume containing the packing and container. The integrated enthalpy flow, from $t=0$ to current time, $t$, is compared with the total enthalpy change for the solid, fluid insulation and wall plus losses to the surroundings. The net enthalpy flow for the fluid is

$$
\Delta H_{1}=\int_{0}^{t} \int_{0}^{A_{0}} \rho c u_{0}[T(R, 0, t)-T(R, L, t)] \mathrm{d} A \mathrm{~d} t .
$$

The expression for the solid, fluid, wall and losses is

$$
\begin{aligned}
\Delta H_{2}= & \int_{0}^{L} \int_{0}^{A_{0}} \rho_{\mathrm{s}} c_{\mathrm{s}}(1-\varepsilon)[\chi(R, x, t)-\chi(R, x, 0)] \mathrm{d} A \mathrm{~d} x \\
& +\int_{0}^{L} \int_{0}^{A_{0}} \rho c \varepsilon[T(R, x, t)-T(R, x, 0)] \mathrm{d} A \mathrm{~d} x \\
& +\int_{0}^{L} \rho_{\mathrm{w}} c_{\mathrm{w}} \pi\left(R_{\mathrm{w}}^{2}-R_{0}^{2}\right)[\psi(x, t)-\psi(x, 0)] \mathrm{d} x \\
& +\int_{0}^{t} \int_{0}^{L} U_{\infty} 2 \pi R_{\mathrm{w}}\left[\psi(x, t)-T_{\infty}\right] \mathrm{d} x \mathrm{~d} t .
\end{aligned}
$$

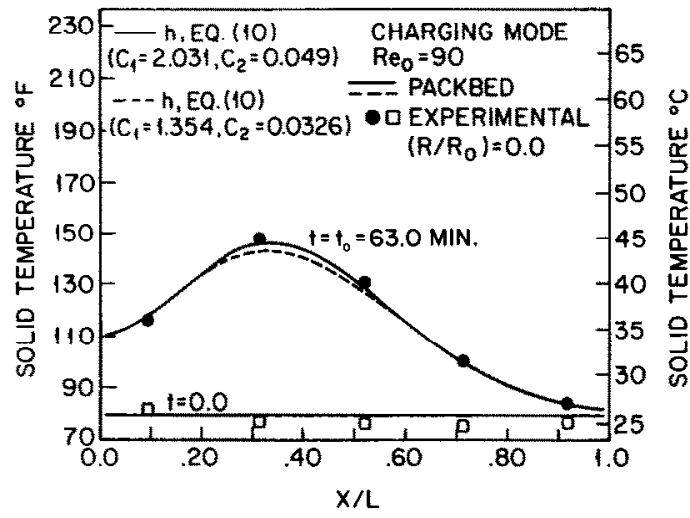

Frg. 5. Effect of heat transfer coefficient on computed solid temperatures.

The quantity

$$
\frac{\Delta H_{2}-\Delta H_{1}}{\Delta H_{1}} \times 100
$$

is the percentage error in the overall energy balance. After several time steps during a computation, the error drops to approximately $\pm 2.0 \%$, and remains essentially constant at this value to $t=t_{0}$, the total charging or recovery time.

\section{Temperature distributions}

Figure 5 shows solid temperatures for spheres located at the centerlinc in the present experimental bed compared with values predicted by PACKBED. The bed is subject to a time-varying inlet fluid temperature. The two curves in Fig. 5 are for values of $h$ computed from equation (10) with $C_{1}=1.354$ and $C_{2}=0.0326$ and also from equation (10) with each of these constants increased by $50 \%$ to values of 2.031 and 0.049 , respectively. Although the influence of changes in $h$ is small, it is clear that axial thermal dispersion is too great for the nominal $h$ values: better agreement is obtained when axial thermal dispersion is decreased by using a higher value of $h$, which at these Reynolds numbers determines the degree of axial thermal

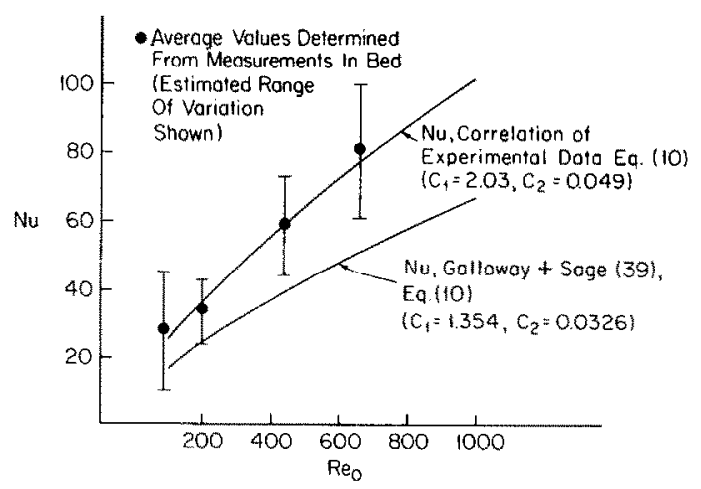

Fig. 6. Comparison of measured Nusselt number with literature values. 


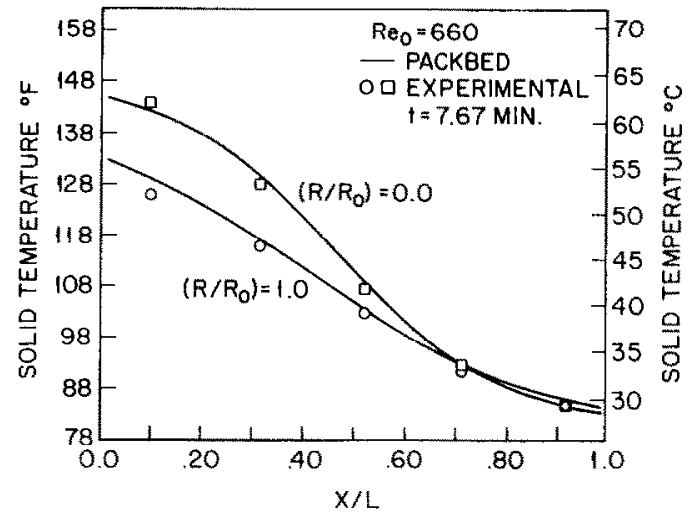

Fig. 7. Measured and computed solid temperature response for two radial positions. Step-change in inlet fluid temperature.

dispersion. Numerical experiments with PACKBED indicate that over a reasonable range of values, $k_{\mathrm{e}}^{x}$ has a negligible effect on the shape of the temperature curves for air-glass systems. The ratio $\rho_{\mathrm{s}} c_{\mathrm{s}} / \rho c$ influences the sensitivity of the system to changes in $k_{\mathrm{e}}^{x}$ and $h$. For this system, $\rho_{\mathrm{s}} c_{\mathrm{s}} / \rho c>1600$. Additional data taken for step changes in inlet fluid temperature, at Reynolds numbers of $90,200,430$ and 660 each confirm this effect of $h$ on the axial thermal dispersion. For the remainder of the comparisons the values of $C_{1}$ and $C_{2}$ in equation (10) are taken at the increased values of $C_{1}=2.031$ and $C_{2}=0.049$.

Gross et al. [16], Saez and McCoy [21] and Vanden Broek and Clark [24] have published comparisons of 1-D models with experimental data from various experiments which show similar qualitative results of the effects of $h$ on axial thermal dispersion, due to the under-estimation of the heat transfer coefficient.

Solid-fluid temperature measurements during transient operation provide a means for determining local values of $h$ at particular locations. Figure 6 shows the two correlating equations utilized in this work, along with an average of $\mathrm{Nu}$ determined from the

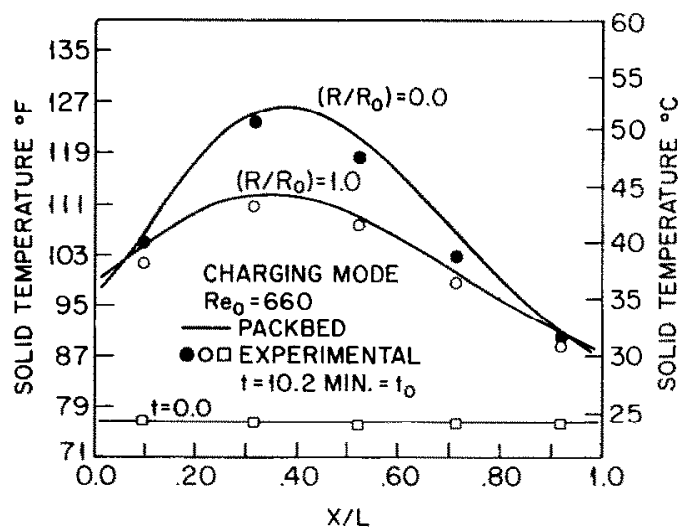

FiG. 8. Measured and computed solid temperature response for two radial positions. Time-varying inlet fluid temperature.

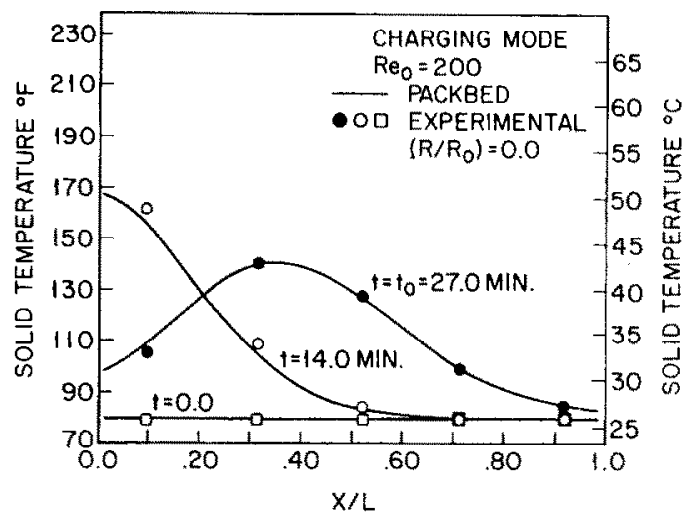

Fig. 9. Measured and computed solid temperature response for $\left(R / R_{0}\right)=0$, charging mode.

measurements at two locations in the bed, $x / L=0.097$ and 0.521 . The resulting average local values of $h$ correspond to values of the Nusselt number higher than those of Galloway and Sage [39], and other widely used correlations, but agree with the values of $\mathrm{Nu}$ which provide the most favorable comparison between the PACKBED model and the experimental measurements of bed temperatures over the range of Reynolds numbers, $R e_{0}=90.660$.

Figure 7 indicates comparisons of solid temperatures at the wall and centerline for a step change in inlet fluid temperature, for a Reynolds number of 660 . The effects of large wall heat capacity, high wall thermal conductivity and a radially distributed inlet fluid temperature create an entirely different character of the thermal response in the near-wall region. A similar comparison, also for a Reynolds number of 660 but for a time-varying inlet fuid temperature is shown in Fig. 8, at the end of the charging period. Agreement with the predicted results is favorable in all cases.

Comparisons for centerline temperature response for a complete charging and recovery cycle are given in Figs. 9 and 10 for a Reynolds number of 200 . The initial

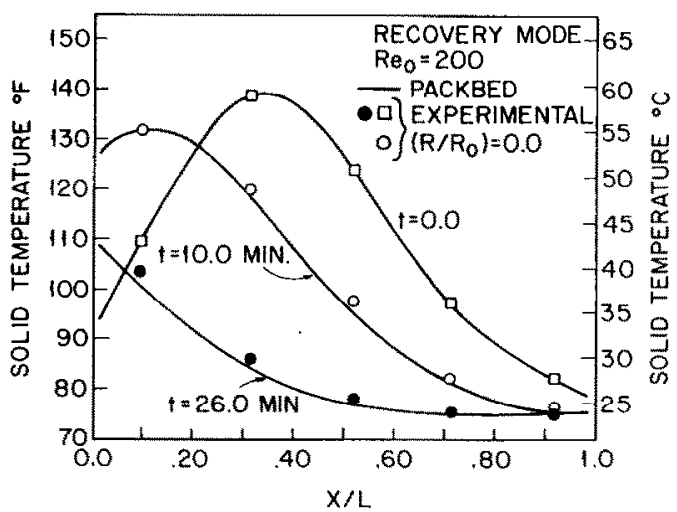

FiG. 10. Measured and computed solid temperature response for $\left(R / R_{0}\right)=0$, recovery mode. 


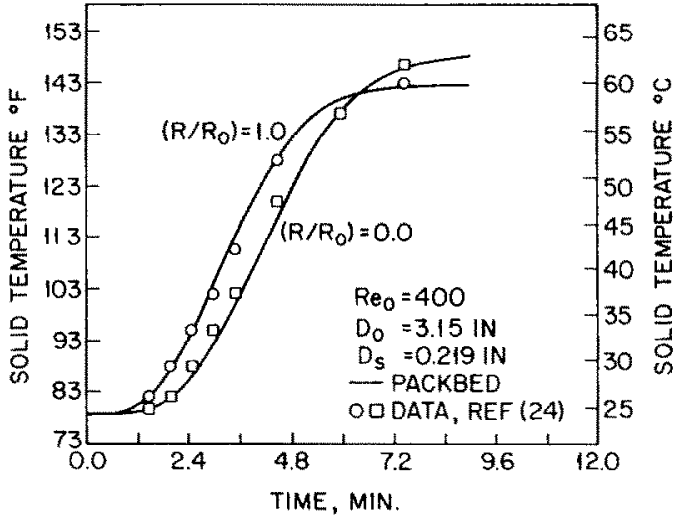

Fig. 11. Measured and computed solid temperature response for the bed of Vanden Broek and Clark [24]. $\bar{\varepsilon}=$ 0.368 ; void fraction variation: $\left(R / R_{0}\right) \leqslant 0.86, \varepsilon=0.35$ $0.86<\left(R / R_{0}\right) \leqslant 1.0, \varepsilon=0.42$.

conditions for recovery are found utilizing a cubic spline fit through the five axial data points at each radial location [43].

Figures 11 and 12 compare solid and mixed mean exit fluid temperatures as measured and predicted by PACKBED for the bed of Vanden Broek and Clark [24]. Flow channeling due to the increased void in the near-wall region causes higher temperatures at the wall during must of the transient period, typical for a system having a low wall heat capacity. The effect of wall thermal losses is apparent at large times in Fig. 11 where the curves cross. However, PACKBED predictions compare favorably with the measurements for this very small bed.

So far as is known, no measurements of void fraction distribution in a bed of randomly sized and shaped particles have extended to the center of the bed. Therefore, Fig. 1, curves B and C, appear to indicate the nature of the void variations in packings of these kind.

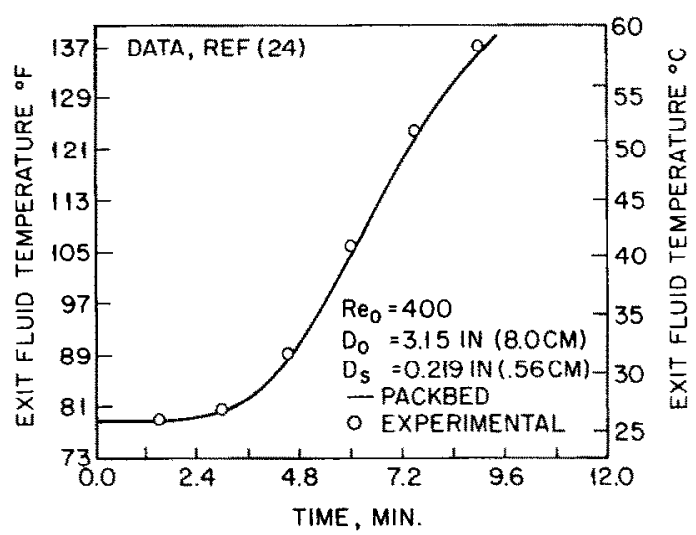

FiG. 12. Measured and computed exit mean fluid temperature for the bed of Vanden Broek and Clark [24].

Utilizing the velocity distribution for a bed of coke, a void distribution is developed from flow distribution predictions, using the value of the average void as a constraint. This void distribution is used to make comparisons of PACKBED with the centerline temperatures measured in a commercial size rock bed, as reported by Jones and Hill [17]. The results, which demonstrate favorable agreement, are given in Fig. 13.

\section{CONCLUSIONS}

This study identifies the effects of void fraction distribution, flow distribution, thermal wall effects and wall energy losses on the dynamic response of a packed bed, subject to an arbitrarily time-varying inlet fluid temperature, for both charging and recovery modes. Thermal dispersion in the axial direction is shown to be determined by the heat transfer coefficient for the Reynolds number range investigated $(90-660)$.

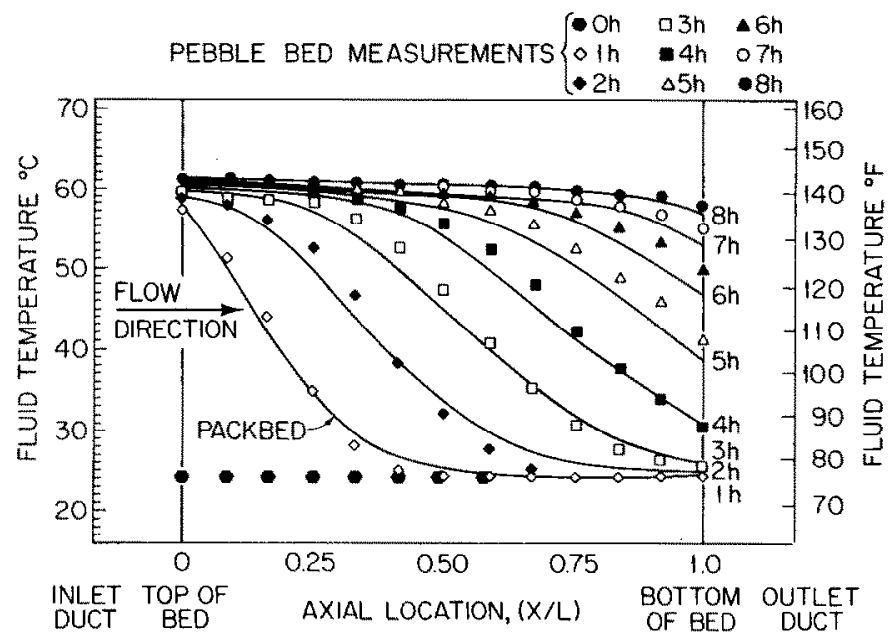

Fig. 13. Comparison of PACKBED predictions with NBS experimental measurements [17] in a commercial size rock bed $\left(R / R_{0}=0\right)$. Void distribution derived from Fig. 1, curve C. 
Measured values of the temperature distributions in three independent experiments indicate that improved agreement with the predictive model is obtained when a Nusselt number correlation is used which is about $50 \%$ greater than current correlations. Separate experimental determinations of the heat transfer coefficient in the bed confirm this.

A predictive numerical model, PACKBED, is developed which incorporates radial variations in void fraction, velocity and transport coefficients. It is valid for fluids having a range of Prandtl numbers. The thermal effects of the wall, including its heat capacity, longitudinal conduction, and losses are incorporated in the model. A new inlet boundary condition is introduced which provides an improved correspondence with the physical conditions at the inlet. The model is capable of predicting the 2-D, transient behavior of a randomly packed bed of uniform spheres for various Reynolds numbers, and for both charging and recovery modes. The model is verified by comparison with experimental data, including data from a commercial size bed packed with natural rock.

Acknowledgements-The authors wish to acknowledge the assistance provided to the first author by a doctoral fellowship from the International Harvester Company, support from the Office of Energy Research and the Department of Mechanical Engineering and Applied Mechanics, University of Michigan. The work of Mr Randy Zoodsma in determining the local heat transfer coefficients is acknowledged and appreciated.

\section{REFERENCES}

1. D. Vortmeyer and R. J. Schaefer, Equivalence of one- andtwo-phase models for heat transfer processes in packed beds: one dimensional theory, Chem. Engng Sci. 29, 485 (1974).

2. M. Riaz, Analytical solutions for single- and-two-phase models of packed-bed thermal storage systems, Trans. Am. Soc. Mech. Engrs, Series C, J. Heat Transfer 99, 489 (1977).

3. T. E. W. Schumann, Heat transfer: a liquid flowing through a porous prism, J. Franklin Inst. 208, 405 (1928).

4. C. C. Furnas, Heat transfer from a gas stream to a bed of broken solids, Ind. Engng Chem. 22 (1), 26 (1930).

5. J.A. Clark and V.S. Arpaci, Dynamic response of a packed bed energy storage system to a time varying inlet temperature, Proc. Solar Heating and Cooling Forum, Miami Beach, Florida (1976).

6. S. A. Mumma and W. C. Marvin, A method of simulating the performance of a pebble bed thermal energy storage and recovery system, ASME Paper No. 76-HT-73, ASME-AICHE Heat Transfer Conf., St. Louis, Missouri (1976).

7. F. W. Schmidt and J. Szego, Transient response of solid sensible heat thermal storage units-singlc fluid, Trans. Am. Soc. Mech. Engrs, Series C, J. Heat Transfer 98 (3), 471 (1976).

8. P. J. Hughes, S. A. Klein and D. J. Close, Packed bed thermal storage models for solar air heating and cooling systems, Trans. Am. Soc. Mech. Engrs, Series C, J. Heat Transfer 98 (2), 336 (1976).

9. D. M. Burch, K. W. Allen and B. A. Peavey, Transient temperature distributions within porous slabs subjected to sudden transpiration heating, Trans. Am. Soc. Mech. Engrs, Series C, J. Heat Transfer 98, 221 (1976).

10. W. J. Yang and C. P. Lee, Dynamic response of solar heat storage systems, ASME Paper No. 74-WA/HT-22 (1974).
11. W. D. Eshleman, C. D. Baird and D. R. Mears, A numerical simulation of heat transfer in rock beds, Proc. 1977 Annual Meeting AS of ISES, Vol. 1, Orlando, Florida (1977).

12. J. A. Clark, K. L. Nabonzy and J. H. Heetderks, ROCKBED-a computer program for thermal energy storage, Proc. 1977 Annual Meeting AS of ISES, Orlando, Florida (1977).

13. G. Von Fuchs, Rock bed computer model, Proc. Solar Energy Storage Options, NTIS Conf. 790328-P2 (1979).

14. B. D. Pomeroy, Thermal energy storage in a packed hed of iron spheres wiih liquid sodium coolant, Solar Energy 23, 513 (1979).

15. H. C. White and S. A. Korpela, On the calculation of the temperature distribution in a packed bed for solar energy applications, Solar Energy 23 (2), 141 (1979).

16. R. J. Gross, C. E. Hickox and C. E. Hackett, Numerical simulation of dual-media thermal energy storage systems, J. Solar Energy Engng 102, 287 (1980).

17. D. E. Jones and J.E. Hill, Testing of pebble-bed and phasechange thermal energy storage devices according to ASHRAE Standard 94-77, NBSIR 79-1937, National Engineering Laboratory, NBS (1980).

18. G. Spiga and M. Spiga, A rigorous solution to a heat transfer, two-phase model in porous media and packed beds, Int. J. Heat Mass Transfer 24, 355 (1981).

19. J. P. Courtier and E. A. Farber, Two applications of a numerical approach of heat transfer process within rock beds, Solar Energy 29, 451 (1982).

20. A. E. Saez and B. J. McCoy, Transient analysis of packedbed thermal storage systems, Int. J. Heat Mass Transfer 26, 49 (1983).

21. A. E. Saez and B. J. McCoy, Dynamic response of a packed bed thermal storage system - a model for solar air heating, Solar Energy 29 (3), 201 (1982).

22. A. Shitzer and M. Levy, Transient behavior of a rock-bed thermal storage system subjected to variable inlet air temperatures: analysis and experimentation, $J$. Solar Energy Engng 105, 200 (1983).

23. N. R. Amundson, Solid-fluid interactions in fixed and moving beds. Fixed beds with small particles, Ind. Engng Chem. 48, 26 (1956).

24. C. Vanden Broek and J. A. Clark, Heat transfer in a column packed with spheres, Heat Exchange and Solar Energy, Von Karman Institute Lecture Series (1980-82).

25. G. F. Robertson and J. C. Cavendish, The effect of flow maldistribution on the thermal response of packed-bed converters and thermal energy storage units, ASME Paper No. 81-HT-59 (1981).

26. J. A. Clark and D. E. Beasley, Dynamic response of a packed-bed thermal storage unit, Progress in Solar Energy, p. 525. American Solar Energy Society (1982).

27. A. R. Balakrishnan, Heat transfer in gas-solid packed bed systems, a critical review, Ind. Engng Chem. Proc. Des. Dev. 18 (1), 441 (1979).

28. H. Martin, Low Peclet number particle-to-fluid heat and mass transfer in packed beds, Chem. Engng Sci. 33, 913 (1978).

29. R. F. Benenati and C. B. Brosilow, Void fraction distribution in beds of spheres, A.I.Ch.E. $J / 8$ (3), 359 (1962).

30. G. J. Beavers, E. M. Sparrow and D. E. Rodenz, Influence of bed size on the flow characteristics and porosity of randomly packed beds of spheres, J. Appl. Mech. 40, 655 (1973).

31. C. E. Schwartz and J. M. Smith, Flow distribution in packed beds, Ind. Engng Chem. 45 (6), 1209 (1953).

32. R. Newell and N. Standish, Velocity distribution in rectangular packed beds and non-ferrous blast furnaces, Metall. Trans. 4, 1851 (1973).

33. H. S. Mickley, K. A. Smith and E. I. Korchak, Fluid flow in packed beds, Chem. Engng Sci. 20, 235 (1965).

34. D. J. Gunn and D. Vortmeyer, Heat transfer in fixed bed 
chemical reactors, Proc. 7 th Int. Heat Transfer Conf., Vol. 6, paper CD3, p. 13, Munich (1982).

35. S. Ergun, Fluid flow through packed columns, Chem. Engng Prog. 48 (2), 89 (1952).

36. V.Stanek and J. Szekely, Three-dimensional flow of fluids through nonuniform packed beds, A.I.Ch.E. Jl 20 (5), 974 (1974).

37. J. Szekely and J. J. Poveromo, Flow maldistribution in packed beds: a comparison of measurements with predictions, A.I.Ch.E. Jl 21 (4), 769 (1975).

38. I. F. MacDonald, M. S. El-Sayed and F. A. L. Dullien, Flow through porous media-the Ergun equation revisited, Ind. Engng Chem. Fundam. 18 (3), 199 (1979).

39. T. R. Galloway and B. H. Sage, A model of the mechanism of transport in packed, distended and fluidized beds, Chem. Engng Sci. 25, 495 (1970).

40. S. Yagi and D. Kunii, Studies on effective thermal conductivities in packed beds, A.I.Ch.E. Jl 3 (3), 373 (1957).

41. K. F. Baddour and C. Y. Yoon, Local radial effective conductivity and the wall effect in packed beds, Chem. Engng Prog. Symp. Ser. 57 (32), 35 (1960).

42. S. Yagi and D. Kunii, Studics on heat transfer ncar wall surfaces in packed beds, A.I.Ch.E. Jl 6 (1), 97 (1960).

43. D. E. Beasley, Dynamic response of a packed bed for thermal energy storage, Ph.D. thesis, University of Michigan (1983).

44. Fluid Meters-Their Theory and Application (5th edn.). ASME (1959).

\title{
REPONSE TRANSITOIRE D'UN LIT FIXE POUR STOCKAGE THERMIQUE
}

Résumé--On présente l'analyse, avec des résultats expérimentaux, de la réponse transitoire d'un lit fixe pour stockage thermique. L'analyse est bidimensionnelle et elle considère à la fois les dispersions thermiques axiale et radiale pour des variations arbitraires de durée et de température radiale du fluide à l'entrée. On inclut les modes de charge et de récupération. On trouve que des variations spatiales de fraction de vide ont une influence sensible sur la réponse dynamique des températures du fluide et du solide. Un modèle numérique inconditionnellement stable prédit la réponse transitoire bidimensionnelle des phases solide et fluide. On considère l'influence des variations radiales de vitesse, des capacités thermiques et des pertes thermiques pariétales. L'analyse est valable pour des fluides à différents nombres de Prandtl. Des mesures expérimentales de température dans un lit fixe de sphères uniformes disposées au hasard se comparent favorablement avec les résultats analytiques avec l'air pour un large domaine de nombres de Reynolds. Des résultats obtenus dans des lits de cailloux indiquent un effet prononcé de la distribution des vides dans de tels systèmes.

\section{DAS ÜBERTRAGUNGSVERHALTEN EINES FESTBETTES ZUR THERMISCHEN ENERGIESPEICHERUNG}

Zusammenfassung-Es wird über eine Berechnung und experimentelle Ergebnisse zum Übertragungsverhalten eines thermischen Festbettspeichers berichtet. Die Berechnung in zwei räumlichen Dimensionen berücksichtigt die Einflüsse von sowohl axialem wie radialem Wärmetransport für beliebige Zeiten und radial veränderliche Fluideintrittstemperaturen. Sowohl Beladungs- wie Entladungsbetrieb können untersucht werden. Unterschiedliche räumliche Anordnungen der Lücken haben, wie sich zeigt, signifikanten Einfluß auf das dynamische Verhalten von Fluid- und Feststofftemperaturen. Ein absolut stabiles numerisches Modell wurde entwickelt, womit sich das zweidimensionale Ü bertragungsverhalten von sowohl der festen wie auch der flüssigen Phase berechnen läßt. Die Einflüsse der radialen Geschwindigkeitsverteilung der Wärmekapazität der Wand sowie der Wärmeverluste durch die Wände werden betrachtet. Die Berechnung ist für Fluide innerhalb eines großen Prandtl-Zahl-Bercichcs gültig. Experimentelle Messungen von Temperaturverteilungen in einem Bett zufälliger Packung aus einheitlichen Kugeln mit Luft als Arbeitsfluid stimmen mit den Rechenergebnissen über einen großen Reynolds-Zahl-Bereich gut überein. Es werden Ergebnisse von Steinspeichern in Normalgröße vorgelegt, die den deutlich ausgeprägten Einfluß der Lückenanordnung in solchen Systemen zeigen.

\section{НЕСТАЦИОНАРНАЯ ХАРАКТЕРИСТИКА ПЛОТНОГО СЛОЯ, ИСПОЛЬЗУЕМОГО В КАЧЕСТВЕ АККУМУЛЯТОРА ТЕПЛОВОЙ ЭНЕРГИИ}

\begin{abstract}
Аннотаци--На основе экспериментальных данных проведен анализ нестационарной характеристики аккумулятора тепловой знергии с плотным слоем дисперсного материала. Анализ проводится в двух пространственных измерениях с учетом как осевого, так и радиального рассеяния тепла за произвольный отрезок времени при радиальных изменениях температуры жидкости на входе. Рассмотрены режимы подвода и отвода тепла. Найдено, что пространственные изменения порозности оказывают суцественне влияние на динамические темпсратурные характеристики жидкости и твердого материала. Разработана устойчивая численная модель для расчета двумерных нестационарных характеристик твердой и жидкой фаз с учетом влияния изменений радиальной скорости, теплоемкости стенки и потерь тепла стенкой. Анализ справедлив для жидкостей, характеризуюшихся различными значениями числа Прандтля. Результаты экспериментальных измерений распределения температур в плотном слое хаотически расположенных однородных сфер, в котором в качестве рабочей жидкости используется воздух, хорошо согласуются с результатами аналитических расчетов в широком диапазоне изменения числа Рейнольдса. Приведены результаты для трехмерных слоев из горных пород, свидетельствующие о важности учета порозности в таких системах.
\end{abstract}

